\title{
Interpolative Rus-Reich-Ćirić Type Contractions via Simulation Functions
}

\author{
Erdal Karapınar and Ravi P. Agarwal
}

\begin{abstract}
In this paper, we introduce the notion of interpolative Rus-ReichĆirić type z-contractions in the setting of complete metric space. We also consider some immediate consequences of our main results.
\end{abstract}

\section{Introduction and Preliminaries}

Let $A$ and $B$ be two Banach spaces. If $A$ and $B$ are algebraically and topologically imbedded in a separated topological linear space, then the pair of $A$ and $B$ is called a Banach couple and is denoted by $(A, B)$. If there is a Banach space $E$ for the Banach couple $(A, B)$ such that the imbedding $A \cap B \subset E \subset A+B$ holds, then $E$ is called and intermediate space of $(A, B)$.

Let $(A, B)$ and $(C, D)$ be two Banach couples. A linear mapping $T$ acting from the space $A+B$ to $C+D$ is called a bounded operator from $(A, B)$ to $(C, D)$ if the restrictions of $T$ to the spaces $A$ and $B$ are bounded operators from $A$ to $C$ and $B$ to $D$, respectively.

We denote by $L(A B, C D)$ the linear space of all bounded operators from the couple $(A, B)$ to the couple $(C, D)$. This is a Banach space in the norm

$$
\|T\|_{L(A B, C D)}=\max \left\{\|T\|_{A \rightarrow B},\|T\|_{C \rightarrow D}\right\} .
$$

Key Words: Simulation function, interpolative contractions, fixed point, metric space, 2010 Mathematics Subject Classification: Primary 47H10; 54H25; Secondary 46T99. Received: 01.01.2019

Accepted: 31.01.2019 
Definition 1.1 ([38]). Let $(A, B)$ and $(C, D)$ be two Banach couples, and $E$ (respectively $F$ ) be intermediate for the spaces of the Banach couple $(A, B)$ (respectively $(C, D)$ ). The triple $(A, B, E)$ is called an interpolation triple, relative to $(C, D, F)$, if every bounded operator from $(A, B)$ to $(C, D)$ maps $E$ to $F$.

A triple $(A, B, E)$ is said to be an interpolation triple of type $\gamma \quad(0 \leq \alpha \leq 1)$ relative to $(C, D, F)$ if it is an interpolation triple and the following inequality holds:

$$
\|T\|_{E \rightarrow F} \leq c\|T\|_{A \rightarrow B}^{\gamma} \cdot\|T\|_{C \rightarrow D}^{1-\gamma}
$$

for some constant $c$.

Very recently, inspired from the interpolation theory, an attractive fixed point result via interpolation was reported in [28]. More precisely, in [28], the notion of interpolative Kannan contraction was introduced as follows: For a metric space $(X, d)$, a mapping $T: X \rightarrow X$ is called an interpolative Kannan contraction if

$$
d(T x, T y) \leq \lambda[d(x, T x)]^{\gamma} \cdot[d(y, T y)]^{1-\gamma},
$$

for all $x, y \in X$ with $x, y \in X \backslash F i x(T)$, where Fix(T) is the set of all fixed point of $T, \lambda \in[0,1)$ and $\gamma \in(0,1)$. The main result in [28] is the following.

Theorem $1.1([28])$. Let $(X, d)$ be a complete metric space and $T$ be an interpolative Kannan type contraction. Then $T$ has a fixed point in $X$.

In [28], an example was given to show that the interpolative Kannan type contraction is more effective than the classical Kannan contraction. This initial result was followed by further extensions see e.g. [29, 30].

On the other hand, in 2015, Khojasteh et al. [37] introduced the notion of simulation function.

Definition 1.2. (See [37]) $A$ simulation function is a mapping $\zeta:[0, \infty) \times$ $[0, \infty) \rightarrow \mathbb{R}$ satisfying the following conditions:

$\left(\zeta_{1}\right) \zeta(0,0)=0 ;$

$\left(\zeta_{2}\right) \zeta(t, s)<s-t$ for all $t, s>0$;

$\left(\zeta_{3}\right)$ if $\left\{t_{n}\right\},\left\{s_{n}\right\}$ are sequences in $(0, \infty)$ such that $\lim _{n \rightarrow \infty} t_{n}=\lim _{n \rightarrow \infty} s_{n}>0$, then

$$
\limsup _{n \rightarrow \infty} \zeta\left(t_{n}, s_{n}\right)<0
$$


In the same year, 2015, this notion was refined by Argoubi et al. [1] by removing the first axiom $\left(\zeta_{1}\right)$. Indeed, it is derived form $\left(\zeta_{2}\right)$. From now on, we consider the simulation functions in the sense of Argoubi et al. [1], that is, $\zeta$ satisfies only $\left(\zeta_{2}\right)$ and $\left(\zeta_{3}\right)$. In the sequel, the the letter $z$ will denote the family of all simulation functions $\zeta:[0, \infty) \times[0, \infty) \rightarrow \mathbb{R}$ that satisfy $\left(\zeta_{2}\right)$ and $\left(\zeta_{3}\right)$. Notice also that the axiom $\left(\zeta_{2}\right)$ yields that

$$
\zeta(t, t)<0 \text { for all } t>0 .
$$

Example 1.1. (See e.g.[37, 40,3]) Let $\phi_{i}:[0, \infty) \rightarrow[0, \infty)$ be continuous functions with $\phi_{i}(t)=0$ if, and only if, $t=0$. For $i=1,2,3,4,5,6$, we define the mappings $\zeta_{i}:[0, \infty) \times[0, \infty) \rightarrow \mathbb{R}$, as follows

(i) $\zeta_{1}(t, s)=\phi_{1}(s)-\phi_{2}(t)$ for all $t, s \in[0, \infty)$, where $\phi_{1}(t)<t \leq \phi_{2}(t)$ for all $t>0$.

(ii) $\zeta_{2}(t, s)=s-\frac{f(t, s)}{g(t, s)} t$ for all $t, s \in[0, \infty)$, where $f, g:[0, \infty)^{2} \rightarrow(0, \infty)$ are two continuous functions with respect to each variable such that $f(t, s)>g(t, s)$ for all $t, s>0$.

(iii) $\zeta_{3}(t, s)=s-\phi_{3}(s)-t$ for all $t, s \in[0, \infty)$.

(iv) If $\varphi:[0, \infty) \rightarrow[0,1)$ is a function such that $\lim \sup _{t \rightarrow r^{+}} \varphi(t)<1$ for all $r>0$, and define

$$
\zeta_{4}(t, s)=s \varphi(s)-t \quad \text { for all } s, t \in[0, \infty) .
$$

(v) If $\eta:[0, \infty) \rightarrow[0, \infty)$ is an upper semi-continuous mapping such that $\eta(t)<t$ for all $t>0$ and $\eta(0)=0$, and define

$$
\zeta_{5}(t, s)=\eta(s)-t \quad \text { for all } s, t \in[0, \infty) \text {. }
$$

(vi) If $\phi:[0, \infty) \rightarrow[0, \infty)$ is a function such that $\int_{0}^{\varepsilon} \phi(u) d u$ exists and $\int_{0}^{\varepsilon} \phi(u) d u>\varepsilon$, for each $\varepsilon>0$, and define

$$
\zeta_{6}(t, s)=s-\int_{0}^{t} \phi(u) d u \quad \text { for all } s, t \in[0, \infty) .
$$

It is clear that each function $\zeta_{i}(i=1,2,3,4,5,6)$ forms a simulation function.

For further examples and more details on simulation functions see e.g. $[37,40,3,4,5,14,15,25,26,27]$. 
Suppose $(X, d)$ is a metric space, $T$ is a self-mapping on $X$ and $\zeta \in \mathcal{Z}$. We say that $T$ is a $Z$-contraction with respect to $\zeta$ [37], if

$$
\zeta(d(T x, T y), d(x, y)) \geq 0 \quad \text { for all } x, y \in X \text {. }
$$

Again from $\left(\zeta_{2}\right)$, we have the following inequality

$$
d(T x, T y) \neq d(x, y) \text { for all distinct } x, y \in X .
$$

Thus, we conclude that $T$ cannot be an isometry whenever $T$ is a $Z$-contraction. In other words, if a $Z$-contraction $T$ in a metric space has a fixed point, then it is necessarily unique.

Theorem 1.2. Every Z-contraction on a complete metric space has a unique fixed point.

The concept of comparison function is introduced by Rus [42] and it has been extensively studied by several of authors to expand more general form of contraction type mappings.

Definition 1.3. [42] An increasing function $\phi:[0, \infty) \rightarrow[0, \infty)$ is said to be a comparison if $\phi^{n}(t) \rightarrow 0$ as $n \rightarrow \infty$ for every $t \in[0, \infty)$, where $\phi^{n}$ is the $n$-th iterate of $\phi$.

The collection of all comparison functions will be denoted by $\Phi$.

Let $\Psi$ be the family of nondecreasing functions $\psi:[0, \infty) \rightarrow[0, \infty)$ satisfying the following condition :

$\left(\Psi_{2}\right) \sum_{n=1}^{+\infty} \psi^{n}(t)<\infty$ for all $t>0$, where $\psi^{n}$ is the $n^{\text {th }}$ iterate of $\psi$.

The functions in the class of $\Psi$ are called $(c)$-comparison functions and hence $\Psi \subset \Phi$. Fundamental properties of $(c)$-comparison functions are collected below:

Lemma 1.1. (See e.g. [42]) If $\psi \in \Psi$, then the following hold:

(i) $\left(\psi^{n}(t)\right)_{n \in \mathbb{N}}$ converges to 0 as $n \rightarrow \infty$ for all $t \in \mathbb{R}^{+}$;

(ii) $\psi(t)<t$, for any $t \in \mathbb{R}^{+}$;

(iii) $\psi$ is continuous at 0 ;

(iv) the series $\sum_{k=1}^{\infty} \psi^{k}(t)$ converges for any $t \in \mathbb{R}^{+}$. 
The notion of $\alpha$-admissible mappings [41] and the concept of triangular $\alpha$-admissible mappings [36] were reconsidered and refined by Popescu [39] in the following way:

Definition 1.4. [39] Let $\alpha: X \times X \rightarrow[0, \infty)$ be a mapping and $X \neq \emptyset$. $A$ self-mapping $T: X \rightarrow X$ is said to be an $\alpha$-orbital admissible if for all $s \in X$, we have

$$
\alpha(s, T s) \geq 1 \Rightarrow \alpha\left(T s, T^{2} s\right) \geq 1 .
$$

Furthermore, an $\alpha$-orbital admissible mapping $T$ is called triangular $\alpha$-orbital admissible if it holds the following condition:

(TO) $\alpha(s, t) \geq 1$ and $\alpha(s, T t) \geq 1$ implies that $\alpha(s, T t) \geq 1$, for all $s, t \in X$.

It is obvious that each $\alpha$-admissible mapping is an $\alpha$-orbital admissible mapping but not the converse see e.g. [39]. For further attractive results, more examples with details see e.g. [2, 4]-[9]-[10]-[13],[17],[22],[18],[19], [36], [23], [24] and the references therein.

In this paper, we introduce a new interpolative contraction by using the simulation function together with the admissible mappings in the context of complete metric spaces. More precisely, we shall revisit one of the the renowned results in the fixed point theory that was proved independently by Rus, Reich and Ćirić see e.g. [43, 44, 45, 46, 47]. For the sake of the completeness of the paper, we recollect here:

Theorem 1.3. Let $(X, d)$ be a complete metric spaces and $T: X \rightarrow X$ be a Rus-Reich-Ćirić contraction mapping, i.e.,

$$
d(T x, T y) \leq \lambda[d(x, y)+d(x, T x)+d(y, T y)]
$$

for all $x, y \in X$, where $\lambda \in\left[0, \frac{1}{3}\right)$. Then $T$ has a unique fixed point.

Note that the theorem above was proved independently by Rus [46, 47] and Reich [43, 44, 45] and Ćirić. Notice that several variation of Rus-Reich-Cirić contraction (7) can be stated also as

$$
d(T x, T y) \leq a d(x, y)+b d(x, T x)+c d(y, T y)
$$

where $a, b, c$ are nonnegative real numbers such that $0 \leq a+b+c<1$.

\section{Main results}

We start with the following definition. 
Definition 2.1. Let $T$ be a self-mapping defined on a metric space $(X, d)$. If there exist $\zeta \in \mathcal{Z}, \psi \in \Psi, \gamma, \beta \in(0,1)$ with $\gamma+\beta<1$ and $\alpha: X \times X \rightarrow[0, \infty)$ such that

$$
\zeta(\alpha(x, y) d(T x, T y), \psi(R(x, y))) \geq 0 \quad \text { for all } x, y \in X,
$$

where

$$
R(x, y):=[d(x, y)]^{\beta} \cdot[d(x, T x)]^{\gamma} \cdot[d(y, T y)]^{1-\gamma-\beta},
$$

then we say that $T$ is an interpolative Rus-Reich-Cirić type Z-contraction with respect to $\zeta$.

If $\alpha(x, y)=1$, then $T$ turns into a $z$-contraction with respect to $\zeta$.

Remark 2.1. If $T$ is an $\alpha$-admissible Z-contraction with respect to $\zeta$, then

$$
\alpha(x, y) d(T x, T y)<\psi(R(x, y))) \quad \text { for all } x, y \in X .
$$

To prove the assertion, we assume that $x \neq y$. Then $d(x, y)>0$. If $T x=$ Ty, then $\alpha(x, y) d(T x, T y)=0<\psi(R(x, y)))$. Otherwise, $T x \neq T y$, then $d(T x, T y)>0$. If $\alpha(x, y)=0$, then the inequality is satisfied trivially. So assume that $\alpha(x, y)>0$ and applying $\left(\zeta_{2}\right)$ with (8), we derive that

$$
0 \leq \zeta(\alpha(x, y) d(T x, T y), \psi(R(x, y))))<\psi(R(x, y)))-\alpha(x, y) d(T x, T y),
$$

so (9) holds.

We can now state the main result of this paper.

Theorem 2.1. Let $(X, d)$ be a complete metric space, $\zeta \in Z$. If a self-mapping $T: X \rightarrow X$ forms an interpolative Rus-Reich-Cirić type Z-contraction with respect to $\zeta$ and satisfies

(i) $T$ is triangular $\alpha$-orbital admissible,

(ii) there exists $x_{0} \in X$ such that $\alpha\left(x_{0}, T x_{0}\right) \geq 1$,

(iii) $T$ is continuous,

then there exists $u \in X$ such that $T u=u$.

Proof. On account of the assumption (ii), there exists $x_{0} \in X$ such that $\alpha\left(x_{0}, T x_{0}\right) \geq 1$. Starting with this initial point $x_{0} \in X$ an iterative sequence $\left\{x_{n}\right\}$ is constructed by $x_{n+1}=T x_{n}$ for all $n \geq 0$. Throughout the proof, without loss of generality, we assume that

$$
d\left(x_{n}, x_{n+1}\right)>0, \text { for all } n=0,1, \ldots
$$


Indeed, if there exists an $k_{0}$ such that $x_{k_{0}}=x_{k_{0}+1}$, then $u=x_{k_{0}}$ becomes a fixed point of $T$ which completes the proof. Accordingly, we suppose that $x_{n} \neq x_{n+1}$ for all $n$, that is, (10) holds.

By taking the assumption ( $i i)$ into account and by regarding that $T$ is $\alpha$-orbital admissible, we obtain that

$$
\alpha\left(x_{n}, x_{n+1}\right) \geq 1, \text { for all } n=0,1, \ldots
$$

From (8) and (11), it follows that for all $n \geq 1$, we have

$$
\begin{aligned}
0 & \leq \zeta\left(\alpha\left(x_{n}, x_{n-1}\right) d\left(T x_{n}, T x_{n-1}\right), \psi\left(R\left(x_{n}, x_{n-1}\right)\right)\right) \\
& =\zeta\left(\alpha\left(x_{n}, x_{n-1}\right) d\left(x_{n+1}, x_{n}\right), \psi\left(R\left(x_{n}, x_{n-1}\right)\right)\right) \\
& <\psi\left(R\left(x_{n}, x_{n-1}\right)\right)-\alpha\left(x_{n}, x_{n-1}\right) d\left(x_{n+1}, x_{n}\right) .
\end{aligned}
$$

Consequently, we derive that

$$
d\left(x_{n}, x_{n+1}\right) \leq \alpha\left(x_{n}, x_{n-1}\right) d\left(x_{n}, x_{n+1}\right)<\psi\left(R\left(x_{n}, x_{n-1}\right)\right)<R\left(x_{n}, x_{n-1}\right),
$$

for all $n=1,2, \ldots$, where,

$$
\begin{aligned}
R\left(x_{n}, x_{n-1}\right) & =\left[d\left(x_{n}, x_{n-1}\right)\right]^{\beta} \cdot\left[d\left(x_{n}, T x_{n}\right)\right]^{\gamma} \cdot\left[d\left(x_{n-1}, T x_{n-1}\right)\right]^{1-\gamma-\beta} . \\
& =\left[d\left(x_{n}, x_{n-1}\right)\right]^{\beta} \cdot\left[d\left(x_{n}, x_{n+1}\right)\right]^{\gamma} \cdot\left[d\left(x_{n-1}, x_{n}\right)\right]^{1-\gamma-\beta} . \\
& =\cdot\left[d\left(x_{n}, x_{n+1}\right)\right]^{\gamma} \cdot\left[d\left(x_{n-1}, x_{n}\right)\right]^{1-\gamma} .
\end{aligned}
$$

By a simple elimination, the inequality (15) implies that

$$
\left[d\left(x_{n}, x_{n+1}\right)\right]^{1-\gamma} \leq \lambda\left[d\left(x_{n-1}, x_{n}\right)\right]^{1-\gamma} .
$$

Hence, we conclude that the sequence $\left\{d\left(x_{n}, x_{n-1}\right)\right\}$ is non-decreasing and bounded from below by zero. Moreover, we deduce, from the monotonicity of $\left\{d\left(x_{n}, x_{n-1}\right)\right\}$, that $R\left(x_{n}, x_{n-1}\right) \leq d\left(x_{n}, x_{n-1}\right)$ and consequently, the inequality (13) turns into

$$
\begin{aligned}
d\left(x_{n}, x_{n+1}\right) & \leq \alpha\left(x_{n}, x_{n-1}\right) d\left(x_{n}, x_{n+1}\right)<\psi\left(R\left(x_{n}, x_{n-1}\right)\right) \\
& <R\left(x_{n}, x_{n-1}\right) \leq d\left(x_{n}, x_{n-1}\right) .
\end{aligned}
$$

Accordingly, there exists $L \geq 0$ such that $\lim _{n \rightarrow \infty} d\left(x_{n}, x_{n-1}\right)=L \geq 0$. We shall prove that

$$
\lim _{n \rightarrow \infty} d\left(x_{n}, x_{n-1}\right)=0 .
$$

Suppose, on the contrary that $L>0$. Note that from the inequality (15), we derive that

$$
\lim _{n \rightarrow \infty} \alpha\left(x_{n}, x_{n-1}\right) d\left(x_{n}, x_{n+1}\right)=L
$$


and

$$
\lim _{n \rightarrow \infty} R\left(x_{n}, x_{n+1}\right)=L .
$$

Letting $s_{n}=\alpha\left(x_{n}, x_{n-1}\right) d\left(x_{n}, x_{n+1}\right)$ and $t_{n}=R\left(x_{n}, x_{n-1}\right)$ and taking $\left(\zeta_{3}\right)$ into account, we get that

$$
0 \leq \limsup _{n \rightarrow \infty} \zeta\left(\alpha\left(x_{n}, x_{n-1}\right) d\left(x_{n+1}, x_{n}\right), R\left(x_{n}, x_{n-1}\right)\right)<0
$$

which is a contradiction. Thus, we have $L=0$.

Now, we shall prove that the iterative sequence $\left\{x_{n}\right\}$ is Cauchy. Again we use the method of Reductio ad absurdum. Suppose, on the contrary that, $\left\{x_{n}\right\}$ is not a Cauchy sequence. Thus, there exists $\varepsilon>0$, for all $N \in \mathbb{N}$, there exist $n, m \in \mathbb{N}$ with $n>m>N$ and $d\left(x_{m}, x_{n}\right)>\varepsilon$. On the other hand, from (16), there exists $n_{0} \in \mathbb{N}$ such that

$$
d\left(x_{n}, x_{n+1}\right)<\varepsilon \text { for all } n>n_{0} .
$$

Consider two partial subsequences $x_{n_{k}}$ and $x_{m_{k}}$ of $x_{n}$ such that

$$
n_{0} \leq n_{k}<m_{k}<m_{k+1} \text { and } d\left(x_{m_{k}}, x_{n_{k}}\right)>\varepsilon \text { for all } k \text {. }
$$

Notice that

$$
d\left(x_{m_{k-1}}, x_{n_{k}}\right) \leq \varepsilon \text { for all } k,
$$

where $m_{k}$ is chosen as a least number $m \in\left\{n_{k}, n_{k+1}, n_{k+2}, \ldots\right\}$ such that $(21)$ is satisfied. We also mention that $n_{k}+1 \leq m_{k}$ for all $k$.. In fact, the case $n_{k}+1 \leq m_{k}$ is impossible due to $(20),(21)$. Thus, $n_{k}+2 \leq m_{k}$ for all $k$. It yields that

$$
n_{k}+1<m_{k}<m_{k}+1 \text { for all } k .
$$

On account of (21),(22) and the triangle inequality, we derive that

$$
\begin{aligned}
\varepsilon & <d\left(x_{m_{k}}, x_{n_{k}}\right) \leq d\left(x_{m_{k}}, x_{m_{k}-1}\right)+d\left(x_{m_{k}-1}, x_{n_{k}}\right) \\
& \leq d\left(x_{m_{k}}, x_{m_{k}-1}\right)+\varepsilon \text { for all } k .
\end{aligned}
$$

Due to (16), we deduce that

$$
\lim _{k \rightarrow \infty} d\left(x_{m_{k}}, x_{n_{k}}\right)=\varepsilon
$$

Again by the triangle inequality, we derive that

$$
d\left(x_{m_{k}}, x_{n_{k}}\right) \leq d\left(x_{m_{k}}, x_{m_{k}+1}\right)+d\left(x_{m_{k}+1}, x_{n_{k}+1}\right)+d\left(x_{n_{k}+1}, x_{n_{k}}\right) \text { for all } k .
$$

Analogously, we have

$$
d\left(x_{m_{k}+1}, x_{n_{k}+1}\right) \leq d\left(x_{m_{k}+1}, x_{m_{k}}\right)+d\left(x_{m_{k}}, x_{n_{k}}\right)+d\left(x_{n_{k}}, x_{n_{k}+1}\right) \text { for all } k
$$


Combining the two inequalities above together with (16) and (23), we find that

$$
\lim _{k \rightarrow \infty} d\left(x_{m_{k}+1}, x_{n_{k}+1}\right)=\varepsilon .
$$

Particularly, there exists $n_{1} \in \mathbb{N}$ such that for all $k \geq n_{1}$ we have

$$
d\left(x_{m_{k}}, x_{n_{k}}\right)>\frac{\varepsilon}{2}>0 \text { and } d\left(x_{m_{k}+1}, x_{n_{k}+1}\right)>\frac{\varepsilon}{2}>0 .
$$

Moreover, since $T$ is triangular $\alpha$-orbital admissible, we have

$$
\alpha\left(x_{m_{k}}, x_{n_{k}}\right) \geq 1
$$

Regarding the fact $T$ is an $\alpha$-admissible $Z$-contraction with respect to $\zeta$, together with (26) and (27) we get that

$$
\begin{aligned}
0 & \leq \zeta\left(\alpha\left(x_{m_{k}}, x_{n_{k}}\right) d\left(T x_{m_{k}}, T x_{n_{k}}\right), \psi\left(R\left(x_{m_{k}}, x_{n_{k}}\right)\right)\right) \\
& =\zeta\left(\alpha\left(x_{m_{k}}, x_{n_{k}}\right) d\left(x_{m_{k}+1}, x_{n_{k}+1}\right), \psi\left(R\left(x_{m_{k}}, x_{n_{k}}\right)\right)\right) \\
& <\psi\left(R\left(x_{m_{k}}, x_{n_{k}}\right)\right)-\alpha\left(x_{m_{k}}, x_{n_{k}}\right) d\left(x_{m_{k}+1}, x_{n_{k}+1}\right),
\end{aligned}
$$

for all $k \geq n_{1}$, where

$$
\begin{aligned}
R\left(x_{m_{k}}, x_{n_{k}}\right) & =\left[d\left(x_{m_{k}}, x_{n_{k}}\right)\right]^{\beta} \cdot\left[d\left(x_{m_{k}}, T x_{m_{k}}\right)\right]^{\gamma} \cdot\left[d\left(x_{n_{k}}, T x_{n_{k}}\right)\right]^{1-\gamma-\beta} . \dot{ } \\
& =\left[d\left(x_{m_{k}}, x_{n_{k}}\right)\right]^{\beta} \cdot\left[d\left(x_{m_{k}}, x_{m_{k}+1}\right)\right]^{\gamma} \cdot\left[d\left(x_{n_{k}}, x_{n_{k}+1}\right)\right]^{1-\gamma-\beta} .
\end{aligned}
$$

Consequently, we have

$0<d\left(x_{m_{k}+1}, x_{n_{k}+1}\right)<\alpha\left(x_{m_{k}}, x_{n_{k}}\right) d\left(x_{m_{k}+1}, x_{n_{k}+1}\right)<\psi\left(R\left(x_{m_{k}}, x_{n_{k}}\right)\right)<R\left(x_{m_{k}}, x_{n_{k}}\right)$,

for all $k \geq n_{1}$. Letting $n, m \rightarrow \infty$ in the inequality above, and keeping in mind the observations in (16), (30), (25), (28) and (29), we find that

$$
\lim _{k \rightarrow \infty} d\left(x_{m_{k}+1}, x_{n_{k}+1}\right)=0
$$

which is a contradiction. Hence, $\left\{x_{n}\right\}$ is a Cauchy sequence. Owing to the fact that $(X, d)$ is a complete metric space, there exists $u \in X$ such that

$$
\lim _{n \rightarrow \infty} d\left(x_{n}, u\right)=0 .
$$

Since $T$ is continuous, we derive from (31) that

$$
\lim _{n \rightarrow \infty} d\left(x_{n+1}, T u\right)=\lim _{n \rightarrow \infty} d\left(T x_{n}, T u\right)=0 .
$$

From (31), (32) and the uniqueness of the limit, we conclude that $u$ is a fixed point of $T$, that is, $T u=u$. 
Theorem 2.2. Let $(X, d)$ be a complete metric space and let $T: X \rightarrow X$ be an $\alpha$-admissible Z-contraction with respect to $\zeta$. Suppose that

(i) $T$ is triangular $\alpha$-orbital admissible;

(ii) there exists $x_{0} \in X$ such that $\alpha\left(x_{0}, T x_{0}\right) \geq 1$;

(iii) if $\left\{x_{n}\right\}$ is a sequence in $X$ such that $\alpha\left(x_{n}, x_{n+1}\right) \geq 1$ for all $n$ and $x_{n} \rightarrow x \in X$ as $n \rightarrow \infty$, then there exists a subsequence $\left\{x_{n(k)}\right\}$ of $\left\{x_{n}\right\}$ such that $\alpha\left(x_{n(k)}, x\right) \geq 1$ for all $k$.

Then there exists $u \in X$ such that $T u=u$.

Proof. Following the proof of Theorem 2.1, we know that the sequence $\left\{x_{n}\right\}$ defined by $x_{n+1}=T x_{n}$ for all $n \geq 0$, converges for some $u \in X$. From (11) and condition (iii), there exists a subsequence $\left\{x_{n(k)}\right\}$ of $\left\{x_{n}\right\}$ such that $\alpha\left(x_{n(k)}, u\right) \geq 1$ for all $k$. Applying (8), for all $k$, we get that

$$
\begin{aligned}
0 & \leq \zeta\left(\alpha\left(x_{n(k)}, u\right) d\left(T x_{n(k)}, T u\right), \psi\left(R\left(x_{n(k)}, u\right)\right)\right) \\
& =\zeta\left(\alpha\left(x_{n(k)}, u\right) d\left(x_{n(k)+1}, T u\right), \psi\left(R\left(x_{n(k)}, u\right)\right)\right) \\
& <\psi\left(R\left(x_{n(k)}, u\right)\right)-\alpha\left(x_{n(k)}, u\right) d\left(x_{n(k)+1}, T u\right),
\end{aligned}
$$

which is equivalent to

$$
d\left(x_{n(k)+1}, T u\right)=d\left(T x_{n(k)}, T u\right) \leq \alpha\left(x_{n(k)}, u\right) d\left(T x_{n(k)}, T u\right) \leq \psi\left(R\left(x_{n(k)}, u\right)\right) .
$$

Letting $k \rightarrow \infty$ in the above equality, we have $d(u, T u)=0$, that is, $u=$ Tu.

\section{Consequences}

In this section, we shall illustrate that several existing fixed point results in the literature can be derived from our main results by regarding Example 1.1.

If $\psi \in \Psi$ and we define

$$
\zeta_{E}(t, s)=\psi(s)-t \quad \text { for all } s, t \in[0, \infty),
$$

then $\zeta_{E}$ is a simulation function (cf. Example $1.1(\mathrm{v})$ ).

Corollary 3.1. Let $(X, d)$ be a complete metric space, $\zeta \in z$. Let a selfmapping $T: X \rightarrow X$ satisfy

$$
\alpha(x, y) d(T x, T y) \leq \psi(R(x, y)), \text { for all } x, y \in X \backslash F i x(T) .
$$

Suppose also that 
(i) $T$ is triangular $\alpha$-orbital admissible;

(ii) there exists $x_{0} \in X$ such that $\alpha\left(x_{0}, T x_{0}\right) \geq 1$;

(iii) $T$ is continuous.

Then there exists $u \in X$ such that $T u=u$.

Proof. Taking $\zeta_{E}(t, s)=\psi(s)-t$ for all $s, t \in[0, \infty)$ in Theorem 2.1, we get that

$$
\alpha(x, y) d(T x, T y) \leq \psi(R(x, y)), \text { for all }
$$

We skip the details.

Corollary 3.2. Let $(X, d)$ be a complete metric space, $\zeta \in Z$. If a self-mapping $T: X \rightarrow X$ satisfies

$$
d(T x, T y) \leq \psi(R(x, y)), \text { for all } x, y \in X \backslash F i x(T)
$$

then there exists $u \in X$ such that $T u=u$.

Proof. Take $\alpha(x, y)=1$ for all $x, y \in X$ in Corollary 3.1.

Definition 3.1. Let $(X, d)$ be a metric space. We say that the self-mapping $T: X \rightarrow X$ is an interpolative Rus-Reich-Ćirić type contraction, if there exist a constant $\lambda \in[0,1)$ and $\gamma, \beta \in(0,1)$ such that

$$
d(T x, T y) \leq \lambda R(x, y)
$$

for all distinct $x, y \in X \backslash F_{T}(X)$, where

$$
R(x, y):=[d(x, y)]^{\beta} \cdot[d(x, T x)]^{\gamma} \cdot[d(y, T y)]^{1-\gamma-\beta}
$$

Corollary 3.3. Let $(X, d)$ be a complete metric space and $T$ be an interpolative Rus-Reich-Ćirić type contraction. Then $T$ has a fixed point in $X$.

Proof. For $\lambda \in(0,1)$, take $\psi(t)=\lambda$ for all $x, y \in X$ in Corollary 3.2.

Example 3.1. Let $X=\{1,3,4,7\}$ be a set endowed with a standard metric $d(x, y)=|x-y|$.

\begin{tabular}{|c|c|c|c|c|}
\hline$d(x, y)$ & 1 & 3 & 4 & 7 \\
\hline 1 & 0 & 2 & 3 & 6 \\
\hline 3 & 2 & 0 & 1 & 4 \\
\hline 4 & 3 & 1 & 0 & 3 \\
\hline 7 & 6 & 4 & 3 & 0 \\
\hline
\end{tabular}


We define a self-mapping $T$ on $X$ by $T:\left(\begin{array}{llll}1 & 3 & 4 & 7 \\ 4 & 7 & 4 & 3\end{array}\right)$. It is clear that $T$ is not Rus-Reich-Ćirić contraction. Indeed, there is no $\lambda \in\left[0, \frac{1}{3}\right)$ such that the following inequality is fulfilled:

$$
\begin{aligned}
d(T 1, T 3)=d(4,7)=3 & \leq \lambda(d(1,3)+d(T 1,1)+d(3, T 3)) \\
& =\lambda(d(1,3)+d(4,1)+d(3,7)) \\
& =\lambda(2+3+4)=9 \lambda .
\end{aligned}
$$

On the other hand, for $\gamma=\beta=\frac{1}{16}$ and $\lambda=\frac{4}{5}$, the self-mapping $T$ forms an interpolative Rus-Reich-Ciric type contraction and 4 is the desired unique fixed point of $T$. Note that in the setting of interpolative Rus-Reich-Ciric type contraction, the constant lies between 0 and 1 although in the classical version it is restricted with 1/3. Notice also that this constructive example can be imbedded in several known examples.

\section{Conclusion and Discussion}

It is clear that we can list several consequences of our main results by defining the mapping $\zeta$ in a proper way like in the Example 1.1. In particular, inspired from the results in [24], we are able to get several existing fixed point theorems in the various settings (in the context of partially ordered set endowed with a metric, in the setting of cyclic contraction etc.) regarding Theorem 2.1 ( and hence Theorem 2.2 ). We omit the details since they can be easily obtained by verbatim of [24].

\section{Competing interests}

The authors declare that there is no conflict of interests regarding the publication of this article.

\section{Authors' contributions}

All authors contributed equally and significantly in writing this article. All authors read and approved the final manuscript.

\section{References}

[1] H. Argoubi, B. Samet, C. Vetro, Nonlinear contractions involving simulation functions in a metric space with a partial order, J. Nonlinear Sci. Appl. 8 (2015), 1082-1094. 
[2] U. Aksoy, E. Karapinar, İ. M. Erhan, Fixed points of generalized $\alpha$ admissible contractions on $b$-metric spaces with an application to boundary value problems, J.Nonlinear and Convex A., 17 (2016). No: 6, 10951108

[3] H.H. Alsulami, E. Karapınar, F. Khojasteh, A.F. Roldán-López-deHierro, A proposal to the study of contractions in quasi-metric spaces, Discrete Dynamics in Nature and Society 2014, Article ID 269286, 10 pages.

[4] A.S. Alharbi, H.H. Alsulami, E. Karapınar, On the Power of Simulation and Admissible Functions in Metric Fixed Point Theory, J. Funct. Spaces, Volume 2017 (2017), Article ID 2068163, 7 pages

[5] B. Alqahtani, A.Fulga, E. Karapinar, Fixed Point Results On $\Delta$ Symmetric Quasi-Metric Space Via Simulation Function With An Application To Ulam Stability, Mathematics 2018, 6(10), 208;

[6] M.U. Ali, T. Kamram, E. Karapınar, An approach to existence of fixed points of generalized contractive multivalued mappings of integral type via admissible mapping, Abstr. Appl. Anal. 2014, (2014) Article ID 141489 .

[7] M.U. Ali, T. Kamran, E. Karapınar, On $(\alpha, \psi, \eta)$-contractive multivalued mappings, Fixed Point Theory Appl. (2014), 2014:7.

[8] S. Almezel, C.M. Chen, E. Karapınar, V. Rakocev, Fixed point results for various $\alpha$-admissible contractive mappings on metric-like spaces, Abstr. Appl. Anal. 2014 (2014), Article ID 379358.

[9] H. Alsulami, S. Gulyaz, E. Karapınar, I.M. Erhan, Fixed point theorems for a class of $\alpha$-admissible contractions and applications to boundary value problem, Abstr. Appl. Anal. 2014 (2014) Article ID 187031.

[10] M. Arshad, E. Ameer, E. Karapınar, Generalized contractions with triangular $\alpha$-orbital admissible mapping on Branciari metric spaces J. Inequal. Appl. 2016, 2016:63

[11] H. Aydi, E. Karapınar, H. Yazidi, Modified F-Contractions via $\alpha$ Admissible Mappings and Application to Integral Equations, Filomat, 31 (5)( 2017), 1141- 148.

[12] H. Aydi, E. Karapinar, D. Zhang, A note on generalized admissible-MeirKeeler-contractions in the context of generalized metric spaces, Results in Mathematics, 71 (2017) No. 1, 73-92. 
[13] H. Aydi, M. Jellali, E. Karapınar, On fixed point results for $\alpha$-implicit contractions in quasi-metric spaces and consequences, Nonlinear Anal. Model. Control. 21 (1) (2016), 40-56.

[14] H. Aydi, A.Felhi, E. Karapinar, F.A. Alojail, "Fixed points on quasimetric spaces via simulation functions and consequences" Journal of Mathematical Analysis, Volume 9 Issue 2 (2018), Pages 10-24.

[15] H. Aydi, E. Karapınar and V. Rakočević, Nonunique Fixed Point Theorems on $b$-Metric Spaces via Simulation Functions, Jordan Journal of Mathematics and statistics,(in press).

[16] S. Banach, Sur les opérations dans les ensembles abstraits et leur application auxéquations intégrales, Fundamenta Mathematicae, 3 (1922), $133-181$.

[17] C.M. Chen, A. Abkar, S. Ghods, E. Karapınar, Fixed Point Theory for the $\alpha$-Admissible Meir-Keeler Type Set Contractions Having KKM* Property on Almost Convex Sets, Appl. Math. Inf. Sci. 11 (1) (2017), 171-176.

[18] M. Jleli, E. Karapınar, B. Samet, Best proximity points for generalized $\alpha-\psi$-proximal contractive type mappings, J. Appl. Math. 2013 (2013) Article ID 534127, .

[19] M. Jleli, E. Karapınar, B. Samet, Fixed point results for $\alpha-\psi_{\lambda}$ contractions on gauge spaces and applications, Abstr. Appl. Anal. 2013 (2013) Article ID 730825.

[20] Jleli, M., Karapınar, E., Samet, B., Best proximity points for generalized $\alpha-\psi$-proximal contractive type mappings, J. Appl. Math., 2013 (2013) Article ID 534127.

[21] Jleli, M., Karapinar, E., Samet, B., Fixed point results for $\alpha-\psi_{\lambda}$ contractions on gauge spaces and applications, Abstr. Appl. Anal., 2013 (2013) Article Id, 730825.

[22] K. Hammache, E. Karapınar, A. Ould-Hammouda, On Admissible weak contractions in $b$-metric-like space, J. Math. Anal. 8 (3) 2017), 167-180.

[23] E. Karapınar, S. Czerwik, H. Aydi, $(\alpha, \psi)$-Meir-Keeler contraction mappings in generalized $b$-metric spaces, J. Funct. Spaces, Volume 2018 (2018), Article ID 3264620, 4 pages.

[24] E. Karapınar, B. Samet, Generalized $(\alpha-\psi)$-contractive type mappings and related fixed point theorems with applications, Abstr. Appl. Anal. 2012 (2012) Article iD 793486. 
[25] E.Karapinar, A.Roldan, D. Oregan, "Coincidence point theorems on quasi-metric spaces via simulation functions and applications to Gmetric spaces", Journal of Fixed Point Theory and Applications. https://doi.org/10.1007/s11784-018-0582-x

[26] E. Karapinar, F. Khojasteh An approach to best proximity points results via simulation functions, Journal of Fixed Point Theory and Applications, $19(3), 1983-1995,2017$

[27] E. Karapinar, Fixed points results via simulation functions, Filomat, 30(2016) No:8, 2343-2350

[28] E. Karapinar, Revisiting the Kannan type contractions via interpolation, Advances in the Theory of Nonlinear Analysis and its Applications, 2 (2018) No:2, 85-87.

[29] E. Karapinar, R.P. Agarwal, H. Aydi, Interpolative Reich-Rus-Ćirić Type Contractions on Partial Metric Spaces. Mathematics 2018, 6, 256.

[30] E. Karapinar, O.Alqahtani, H. Aydi, On Interpolative Hardy-Rogers Type Contractions, Symmetry, 2019, 11(1), 8;

[31] E. Karapinar, H.H. Alsulami and M. Noorwali, Some extensions for Geragthy type contractive mappings Journal of Inequalities and Applications 2015, 2015:303 (26 September 2015)

[32] E. Karapinar, Discussion on $(\alpha, \psi)$ contractions on generalized metric spaces, Abstr. Appl. Anal., 2014 (2014) Article ID 962784.

[33] E. Karapınar, Fixed points results for $\alpha$-admissible mapping of integral type on generalized metric spaces, Abstr. Appl. Anal., 2014 (2014), Article Id: 141409

[34] E. Karapinar, On $(\alpha, \psi)$ contractions of integral type on generalized metric spaces, in Proceedings of the 9th ISAAC Congress, V. Mityushevand, M. Ruzhansky, Eds., Springer, Krakow, Poland, 2013.

[35] E. Karapinar, B. Samet, Generalized $\alpha-\psi$-contractive type mappings and related fixed point theorems with applications, Abstr. Appl. Anal. 2012 (2012) Article ID 793486.

[36] E. Karapinar, P. Kumam, P. Salimi, On $\alpha-\psi$-Meir-Keeler contractive mappings, Fixed Point Theory Appl. (2013), 2013:94. 
[37] F. Khojasteh, S. Shukla, S. Radenović, A new approach to the study of fixed point theorems via simulation functions, Filomat 29:6 (2015), 1189-194.

[38] Krein, S.G.; Petunin, J.I.; Semenov, E.M. Interpolation Of Linear Operators; American Mathematical Society: Providence, RI, USA, 1978.

[39] O. Popescu, Some new fixed point theorems for $\alpha$-Geraghty contractive type maps in metric spaces, Fixed Point Theory Appl. 2014, 2014:190

[40] A.F. Roldán-López-de-Hierro, E. Karapınar, C. Roldán-López-de-Hierro, J. Martínez-Moreno, Coincidence point theorems on metric spaces via simulation functions, J. Comput. Appl. Math. 275 (2015) 345-355.

[41] B. Samet, C. Vetro, P. Vetro, Fixed point theorem for $\alpha-\psi$ contractive type mappings, Nonlinear Anal. 75 (2012) 2154-2165.

[42] I. A. Rus, Generalized Contractions and Applications, Cluj University Press, Cluj-Napoca, Romania, 2001.

[43] S. Reich, Some remarks concerning contraction mappings, Can. math. Bull. 14 (1971) 121-124 .

[44] S. Reich, Fixed point of contractive functions, Boll. Un. mat. Ital. (4)(1972) no.5, 26-42 .

[45] S. Reich, Kannan's fixed point theorem, Boll. Un. mat. Ital. (4)(1971) no.4, 1-11 .

[46] I.A. Rus, Principles and Applications of the Fixed Point Theory (in Romanian), Editura Dacia, Clui-Napoca, 1979

[47] I.A. Rus, Generalized Contractions and Applications, Cluj University Press, Clui-Napoca, 2001

Erdal Karapinar,

Department Of Medical Research,

China Medical University Hospital,

China Medical University, 40402, Taichung, Taiwan

Email: erdalkarapinar@yahoo.com

Ravi P. Agarwal,

Texas A \& M University-Kingsville 700 University Blvd., MSC 172

Kingsville, Texas 78363-8202, USA

Email: Ravi.Agarwal@tamuk.edu 